\title{
ADENOSINE TRIPHOSPHATASE ACTIVITY IN GLIAL CELLS AND IN NEURONAL PERIKARYA OF EDEMATOUS RAT BRAIN
}

\author{
FEDOR MEDZIHRADSKY, OTTO Z. SELLINGER, PRANEE S. NANDHASRI AND \\ JOSEPHINE C. SANTIAGO
}

Department of Biological Chemistry, Laboratory of Neurochemistry Mental Health Research Institute and Upjohn Center for Clinical Pharmacology, The University of Michigan Medical Center, Ann Arbor, Mich. 48104 (U.S.A.)

(Accepted August 14th, 1973)

\section{SUMMARY}

The activity of $\mathrm{Na}, \mathrm{K}-\mathrm{ATPase}$ and the ouabain insensitive ATP-hydrolyzing activity was studied in fractions of glial cells and of neuronal perikarya isolated in bulk from cortex and subcortical white matter of rats, previously treated with intraperitoneal administration of water. With increasing water load, the cortical $\mathrm{Na}, \mathrm{K}$ ATPase activity markedly decreased in glial cells and was slightly elevated in neuronal perikarya of edematous brain. The Na,K-ATPase of the glial cells and of the neuronal perikarya of white matter, on the other hand, exhibited no significant changes in specific activity. The ouabain-insensitive ATPase activity behaved similarly. It was markedly decreased in cortical glial cells isolated from rats receiving water equaling $20 \%$ or $30 \%$ of their body weight, respectively, whereas no change of the cortical ouabain-insensitive ATPase was observed in the neuronal perikarya.

\section{INTRODUCTION}

Cerebral edema describes a state of enlarged brain volume due to an increase in tissue fluids other than blood. Depending on the etiology of the edematous process, the swelling occurs predominantly in white or gray matter. Although contradictions in the accumulated data persist, the swelling of the gray matter appears to be mostly intracellular in contrast to the predominantly extracellular accumulation of fluid in the white matter ${ }^{16}$. In addition, electron microscopic evidence suggests a differentiation of the edematous process on a cellular level, i.e., predominantly affected glial or neuronal cells $2,7,16,19$.

Characteristic biochemical findings in edematous brain tissue are elevated sodium, chloride and water content, as well as relatively unchanged potassium levels. 
The increase of the ratio sodium/potassium in edematous tissue indicates an impairment of the process responsible for maintaining the extra-intracellular distribution of these ions. Considerable evidence has accumulated for the involvement of the membrane-bound sodium, potassium-activated, magnesium-dependent adenosine triphosphatase ( $\mathrm{Na}, \mathrm{K}-\mathrm{ATPase}$ ) in the active transport of sodium and potassium ${ }^{4,15}$. Whereas no significant change in the total ATPase activity was observed in white matter of rats in which the edematous process was induced by the administration of triethyltin $^{6}$, the activity of the $\mathrm{Na}, \mathrm{K}$-ATPase was increased in the edematous cortex adjacent to a transplanted tumor ${ }^{8}$ and after cortical lesions induced by freezing ${ }^{9}$.

The cellular transport of sodium and potassium is apparently affected in the edematous state. In view of the role of $\mathrm{Na}, \mathrm{K}$-ATPase in this process, and considering the often observed regional differences in brain swelling as well as the unsettled question of the cellular localization of the edematous process, it was of interest to study the ATPase activity in fractions of glial cells and of neuronal perikarya obtained from cerebral cortex and subcortical white matter of edematous rat brain. Brain edema was induced by intraperitoneal administration of water.

\section{METHODS}

\section{Animal experiments}

The conditions for inducing brain swelling were as described by Wasterlain and Posner ${ }^{18}$. Male Sprague-Dawley rats, weighing 180-200 g, were divided into 4 groups of 8-10 animals each. Rats in the control group received 5 units of pitressin intraperitoneally, whereas animals in the other groups were injected with pitressin plus distilled water equaling $10 \%, 20 \%$ and $30 \%$ of their body weight. After the injections, the animals were constantly observed in order to detect possible convulsions. Several animals in the $30 \%$ group showed convulsive movements and were excluded from the study. Two hours after the administration, the rats were decapitated and their heads placed on ice. The removal of the brain and further dissection were carried out at $4{ }^{\circ} \mathrm{C}$. After the separation of the cerebrum, the cortical shell was dissected and adhering parts of the corpus callosum snipped off with scissors. The white matter used in this study consisted of subcortical tissue excluding most of the corpus callosum. The dissected tissue was freed from adhering blood vessels and the cortices and subcortical white matter of 8-10 animals were pooled.

\section{Isolation of cellular fractions}

Fractions of glial cells and neuronal perikarya were prepared by the procedure of Sellinger et al. ${ }^{14}$, which involves sieving of the tissue through nylon cloth of decreasing pore sizes followed by centrifugation in sucrose-Ficoll gradients. The pellets representing the two cellular populations were kept until analysis at $-70^{\circ} \mathrm{C}$.

\section{Assay of enzymatic activity}

Details of these procedures were described previously ${ }^{11}$. Prior to the assay, the cells were suspended in $50 \mathrm{~m} M$ imidazole- $\mathrm{HCl}$ buffer $(\mathrm{pH} \mathrm{7.0)}$ and subjected to 
repeated freezing $\left(-70^{\circ} \mathrm{C}\right)$ and thawing. ATPase activity was assayed in the presence and absence of $0.2 \mathrm{mM}$ ouabain by the spectrophotometric determination of inorganic phosphate using a procedure which allowed the estimation of $0.5-5 \mu \mathrm{g}$ of phosphorus ${ }^{11}$. Protein was determined according to Lowry et al. ${ }^{10}$ by an adaptation applicable to $0.3-5 \mu \mathrm{g}$ of protein ${ }^{11}$.

RESULTS

As shown in Figs. 1 and 2, significant changes in enzymatic activity were obtained only in cells isolated from the cerebral cortex. Whereas considerable effects were obtained in cortical glial cells, neurons from this tissue appeared to be affected to a lesser degree. In addition, in all experiments the ATPase activity of the glial cells was markedly higher than that of the neuronal perikarya.

\section{Na,K-ATPase (Fig. 1)}

A marked decrease of this enzymatic activity was obtained in the glial cells from cerebral cortex. The lowering of its specific activity correlated with the increase in the water load. Whereas in rats receiving $10 \%$ water no change in enzyme activity was observed as compared to the control group, the Na,K-ATPase activity fell markedly when the water load increased to $20 \%$ and continued to decrease in the $30 \%$ group.

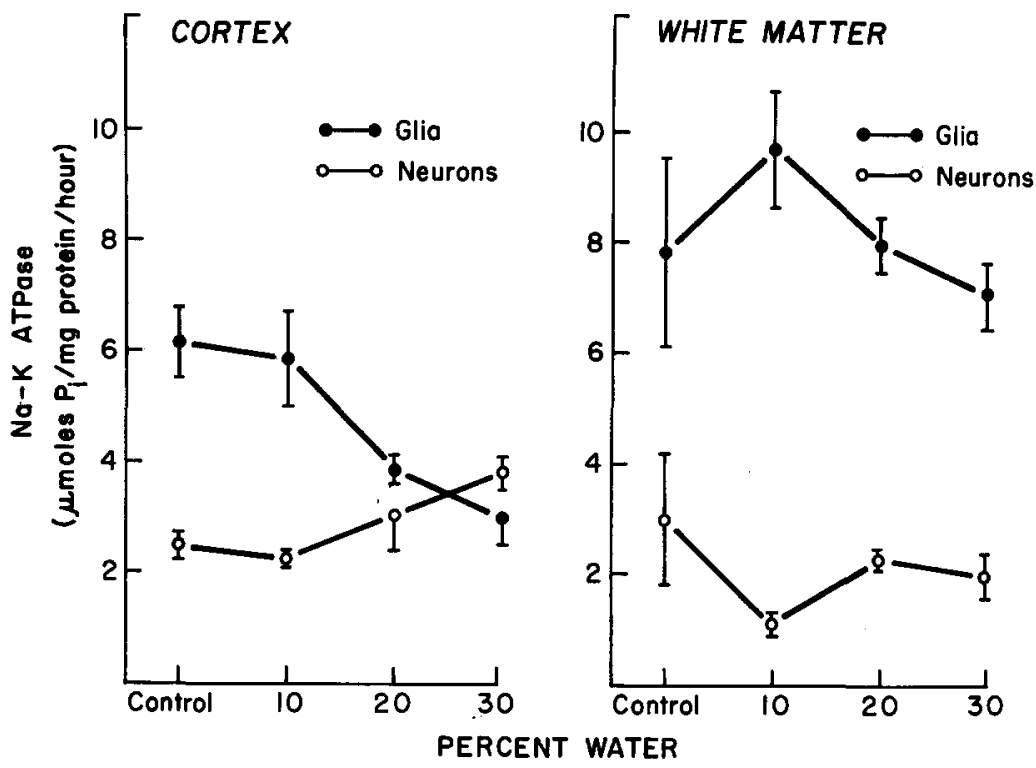

Fig. 1. Sodium-potassium activated adenosine triphosphatase (Na,K-ATPase) activity in fractions of glial cells and of neuronal perikarya isolated in bulk from cortex and subcortical white matter of edematous rat brain. ATPase activity was determined in the presence of $0.2 \mathrm{~m} M$ ouabain as described in the text. Specific enzyme activity is plotted against amount of water administered intraperitoneally. Given is the mean \pm S.D. of 4 separate experiments. In each experiment, brain cells were separated from pooled tissue of 8-10 rats. 


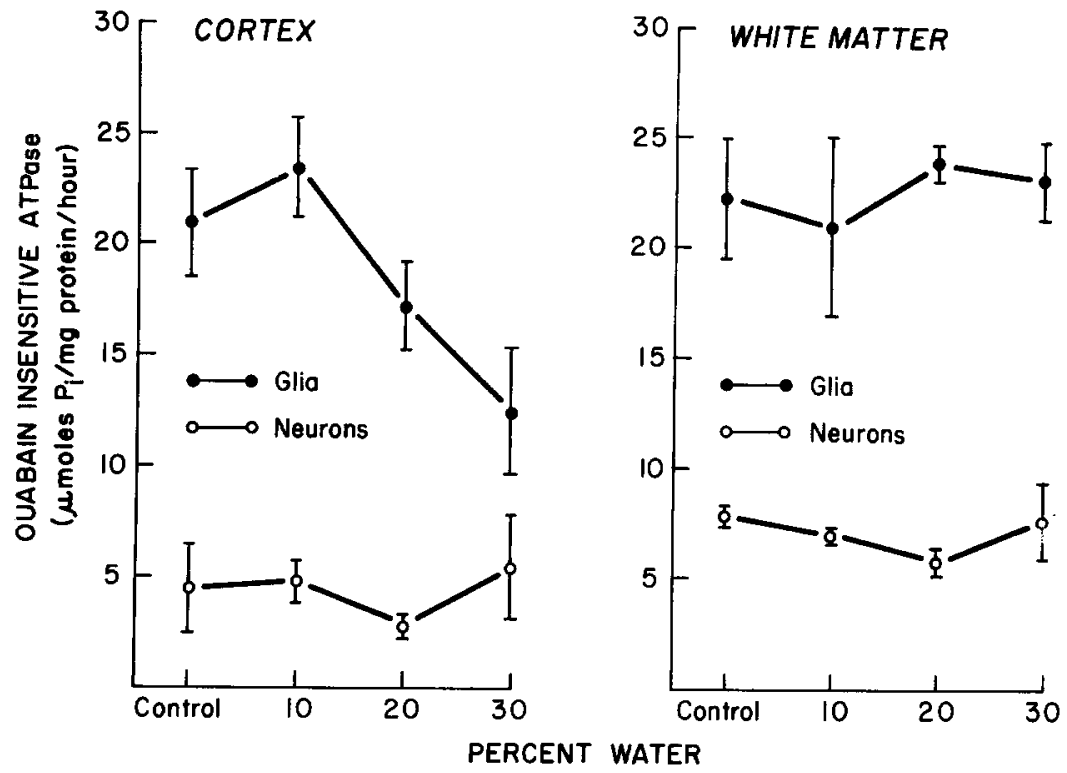

Fig. 2. Ouabain-insensitive ATPase activity in fractions of glial cells and of neuronal perikarya isolated in bulk from cortex and subcortical white matter of edematous rat brain. ATPase activity was determined as described in the text. Specific enzyme activity is plotted against amount of water administered intraperitoneally. Given is the mean \pm S.D. of 4 separate experiments. In each experiment, brain cells were separated from pooled tissue of 8-10 rats.

Under conditions of $30 \%$ water administration, the specific activity of the neuronal $\mathrm{Na}, \mathrm{K}-\mathrm{ATPa} e$ in the cerebral cortex was higher than that of the controls or of the $10 \%$ and $20 \%$ groups.

Ouabain-insensitive ATPase (Fig. 2)

A considerable decrease of this enzymatic activity was noted in cortical glial cells. As with Na,K-ATPase, the sharp fall occurred in the $20 \%$ group and continued with an increasing water load. The ouabain-insensitive ATPase activity in cortical neurons as well as in both cellular fractions from the subcortical white matter was unaffected by the water treatment.

\section{DISCUSSION}

Water intoxication in small laboratory animals has been induced by i.v. infusion of hypotonic solutions and of water over a prolonged period ${ }^{1,17}$. Induction was achieved 70-90 min after the start of the infusion, as shown by corresponding abrupt changes in EEG activity and CSF pressure ${ }^{1}$. Intraperitoneal injection of water produces significant swelling of the brain ${ }^{18,19}$. Two hours after the administration, the intensity of cerebral edema, as measured by the water content of the tissue, was directly proportional to the water load. However, under the same experimental conditions brain swelled less than did muscle and liver. An electron microscopic 
examination of the white matter in water intoxication revealed selectively affected brain cells: the swelling was confined to astrocytes, whereas oligodendrocytes and neurons appeared intact ${ }^{19}$. An explanation of the above findings, as suggested by Wasterlain and Posner ${ }^{18}$, could be the existence of a protective mechanism in brain cells which decreases the osmolar gradient between blood and brain, i.e., a mechanism for the elimination of excessive intracellular ions (e.g., sodium). However, the experimental evidence for an actual loss of electrolytes in hydrated brain tissue is not unequivocal: the reported differences in the ionic contents of edematous and control brain tissue are not significant ${ }^{17,18}$.

Strong evidence suggests the involvement of the membrane-bound Na,K-ATPase in the transport of sodium and potassium across the plasma membrane of cells ${ }^{4,15}$. By extruding excess sodium accumulated as a consequence of the osmolar gradient created by the intraperitoneal water administration, the Na,K-ATPase could represent the osmotic regulatory system and any enhancement of this system would be reflected in an increased specific activity of this enzyme. Indeed, the activity of the $\mathrm{Na}$, $\mathrm{K}$-ATPase in many tissues was found to increase in situations requiring a higher rate of $\mathrm{Na}-\mathrm{K}$ transport ${ }^{3,5,9,12}$. Krigman and $\mathrm{Hunt}^{8}$ reported increased sodium and water content in both gray and white matter of brain after the intracerebral transplantation of HC 305 glioma. Although these changes were particularly pronounced in white matter, the activity of the Na,K-ATPase was elevated only in the cortex of the edematous brain. It was suggested ${ }^{8}$ that this increase in enzyme activity occurred only in neurons where it represents a compensatory mechanism for the maintenance of the ionic integrity in these cells.

In our study, the marked effects were obtained in cortical glial cells, in which the activities of both the Na,K-ATPase and of the ouabain-insensitive ATPase were considerably decreased (Figs. 1 and 2). These findings correlate well with electron microscopic evidence showing, in edema produced by water intoxication, a selective swelling of astrocytes in both gray and white matter and the normal appearance of neurons and oligodendrocytes ${ }^{19}$. Therefore, despite the slightly increased Na,K-ATPase activity in cortical neurons observed in the $30 \%$ group (Fig. 1), our results do not show a prevailing role of a compensatory regulation of the Na,K-ATPase in edematous brain cells, but rather denote a progressive inactivation of the measured glial enzymes with increasing water load, i.e., in response to a progressively steeper osmotic gradient. Whether the inactivation reflects alterations of protein structure coupled to membrane damage, or represents changes in the composition of the glial fraction isolated from edematous brain, cannot be decided at this time.

The observed slight increase of the Na,K-ATPase (but not of the ouabaininsensitive ATPase) in cortical neurons from edematous brain (Fig. 1) could reflect the operation of a compensatory mechanism as discussed above, the effect of which would be the prevention of cellular swelling. However, such an interpretation of a compensatory regulation of the $\mathrm{Na}, \mathrm{K}$-ATPase activity in neurons but not in glia of the edematous brain is not unequivocal since, as must be emphasized, the two isolated cellular fractions represent structurally well preserved glial cells on one hand and neuronal perikarya virtually deprived of processes on the other. Obviously, in the 
latter fraction much of the membrane-bound $\mathrm{Na}, \mathrm{K}$-ATPase was unavailable for analysis, thus limiting a complete evaluation of neuronal $\mathrm{Na}, \mathrm{K}-\mathrm{ATP}$ ase. Nevertheless, our experiments indicate that in glia ATPase activity markedly decreases with increasing severity of the edema, in agreement with the electron microscopic findings of Wasterlain and Torack ${ }^{19}$.

Observations in the ultrastructural study ${ }^{19}$ of a selective effect of the edematous process on astrocytes also revealed the presence of unaffected glial cells which are likely to exhibit normal ATPase activity. It is therefore conceivable that the extent of the decrease in ATPase activity of cortical glial cells (Figs. 1 and 2) is limited by representing only the events in the affected glial cells.

The apparent discrepancy between the electron microscopic evidence and our data regarding the involvement in the pathogenic process of gray and white matter could be based on differences among the examined tissues. Whereas in our experiments brain was dissected into cortex and subcortical white matter, the electron microscopic study distinguished between gray and white matter of the brain hemispheres. Good agreement between the two studies exists in regard to the quantitative effect of the water loads. In our experiments, changes in enzyme activities were obtained only in the $20 \%$ and $30 \%$ group, in agreement with the absence of ultrastructurally demonstrable swelling in the $10 \%$ group $^{19}$.

The markedly higher ATPase activity of glial cells as compared to that of neuronal perikarya is a confirmation of our earlier observations ${ }^{11,12}$. It should again be emphasized that this difference may partially reflect the absence of the dendritic and synaptic elements in the neuronal perikaryal fraction as opposed to the well preserved processes in the glial cell fraction.

As with Na,K-ATPase, a decrease of the ouabain-insensitive ATPase activity (Fig. 2) was observed only in cortical glial cells isolated from brains of rats receiving high doses of water $(20 \%$ and $30 \%)$. The fall of this enzymatic activity reflects a decrease in the ATP-hydrolyzing capacity which in turn represents an impairment of the energy metabolism in the affected cells. In edema of various etiology, affected brain tissue was characterized by a strongly depleted energetic state ${ }^{13}$.

\section{ACKNOWLEDGEMENTS}

The skillful assistance of Mrs. Frances Birko and Mr. Michael J. Marks in part of this work is gratefully acknowledged.

This study was supported in part by Research Grants 2 P11 GM-15559 and RR-05383 (F.M.) and NS-06294 (O.Z.S.) from the U.S. Public Health Service.

\section{REFERENCES}

1 Dodge, P. R., Crawford, J. D., And Probsr, J. H., Studies in experimental water intoxication, Arch. Neurol. (Chic.), 3 (1960) 513-529.

2 Gerschenfeld, H. M., Wald, F., Zadunaisky, J. A., and De Robertis, E. D. P., Function of astroglia in the water-ion metabolism of the central nervous system. An electron microscope study, Neurology (Minneap.), 9 (1959) 412-425. 
3 Huttenlocher, P. R., And Rawson, M. D., Neuronal activity and adenosine triphosphatase in immature cerebral cortex, Exp. Neurol., 22 (1968) 118-129.

$4 \mathrm{Katz}$, A. I., AND EPSTEIN, F. H., Physiologic role of sodium-potassium-activated adenosine triphosphatase in the transport of cations across biologic membranes, New Engl. J. Med., 278 (1967) 253-261.

5 Katz, A. I., AND Epstein, F. H., Role of sodium-potassium-activated adenosine triphosphatase in absorption of sodium in kidney, $J$. clin. Invest., 46 (1967) 1999-2011.

6 Katzman, R., Alen, F., And Wilson, C., Further observations on triethyltin edema, Arch. Neurol. (Chic.), 9 (1963) 178-187.

7 Katzman, R., Gonatas, N., AND Levine, S., Electrolytes and fluids in experimental focal leukoencephalopathy, Neurology (Minneap.), 10 (1964) 58-65.

8 Krigman, M. R., AND HuRT, J. P., Na-K-ATPase activity in focal cerebral edema associated with an experimental glioma in guinea pigs, J. Neuropath. exp. Neurol., 29 (1970) 285-295.

9 Lewin, E., AND MCCrimmon, A., ATPase activity in discharging cortical lesions induced by freezing, Arch. Neurol. (Chic.), 16 (1967) 321-325.

10 Lowry, O. H., Rosebrough, N. J., Farr, A. L., and Randall, R. J., Protein measurements with the Folin phenol reagent, J. biol. Chem., 193 (1951) 265-275.

11 Medzihr adsky, F., NAndhasri, P. S., Idoyaga-Vargas, V., and Sellinger, O. Z., A comparison of the ATPase activity of the glial cell fraction and the neuronal perikaryal fraction isolated in bulk from rat cerebral cortex, $J$. Neurochem., 18 (1971) 1599-1603.

12 Medzihradsky, F., Sellinger, O. Z., Nandhasri, P. S., And Santiago, J. C., ATPase activity in glial cells and in neuronal perikarya of rat cerebral cortex during early postnatal development, J. Neurochem., 19 (1972) 543-545.

13 Reulen, H. J., Medzihradsky, F., Enzenbach, R., Marguth, F., And Brendel, W., Electrolytes, fluids and energy metabolism in human cerebral edema, Arch. Neurol. (Chic.), 21 (1968) $517-525$.

14 Sellinger, O. Z., Azcurra, J. M., Johnson, D. E., Ohlsson, W. G., And Lodin, Z., Independence of protein synthesis and drug uptake in nerve cell bodies and glial cells isolated by a new technique, Nature New Biol., 230 (1971) 253-256.

15 Skou, J. C., Enzymatic basis for active transport of $\mathrm{Na}^{+}$and $\mathrm{K}^{+}$across cell membrane, Physio . Rev., 45 (1965) 596-617.

16 Stein, E. W., The contribution of the laboratory to an understanding of the cerebral edemas, Neurology (Minneap.), 15 (1965) 902-912.

17 Van Harreveld, A., Collewyn, H., and Malhotra, S. K., Water, electrolytes and extracellular space in hydrated and dehydrated brains, Amer. J. Physiol., 210 (1966) 251-256.

18 Wasterlain, C. G., and Posner, J. B., Cerebral edema in water intoxication. I. Clinical and chemical observations, Arch. Neurol. (Chic.), 19 (1968) 71-78.

19 Wasterlain, C. G., And Torack, R. M., Cerebral edema in water intoxication. II. An ultrastructural study, Arch. Neurol. (Chic.), 19 (1968) 79-87. 